(Civil Engineeering, Elektrical Engineeering and Industrial Engineeering)

Vol. 17, No : 2, Oktober 2020 , p-ISSN:1907-5243, e-ISSN: 2655-8416

\title{
ENERGY NOT SOLD(ENS) PADA IMPLEMENTASI FAULT DETECTION INSULATION AND RESTORATION (FDIR) PT. PLN DI PENYULANG OGAN GARDU INDUK SEI JUARO
}

\author{
Normaliaty Fithri ${ }^{1}$, Endah Fitriani ${ }^{2}$ \\ 1,2Electrical Enginering,Bina Darma University, Palembang, Indonesia \\ Sur-el : Normaliaty@,binadarma.ac.id ${ }^{1}$, endahfitriani@,binadarma.ac.id ${ }^{2}$
}

\begin{abstract}
As an effort to carry out sustainability services with efficient distribution of electricity quality, a system that can provide a form of service with reliable distribution system is implemented that can provide an overview of the narrowing of the territory of the extent of the disturbance that is happening. With the application of the Fault Detection Insulation and Restoration (FDIR) system in the feeder with a relatively fast and automatic maneuver process, it can reduce the duration of the outage which can also directly determine the point of disturbance when a disturbance occurs in real time. If there is a disturbance in the Ogan feeder, the FDIR automation system will immediately isolate the network by manewvering the Kedondong feeder in less than one minute, so that by calculating ENS you can get the benefit of reducing the Energy not sold (ENS) value.
\end{abstract}

Keywords: Fault Detection Insulation And Restoration (FDIR), Energy Not Sold (ENS), interference, SAIDI

\section{PENDAHULUAN}

Peningkatan keberlangsungan mutu terhadap pelayanan penyaluran tenaga listrik ke pelanggan, merupakan tujuan dari PT.PLN (Persero). Tugas utama dalam pelayanan ini yaitu menekan jumlah gangguan pada jaringan listrik dan mengurangi lamanya pemadaman. Gangguan jaringan secara umum dapat diklasifikasikan kepada beberapa gangguan. Yakni gangguan pada Saluran Rumah (SR) termasuk APP, Jaringan Tegangan Rendah (JTR), Jaringan Tegangan Menengah (JTM), Gardu Trafo Distribusi (GTD). Dalam hal ini menjadi tanggung jawab pelayanan teknik untuk terus melakukan perbaikan dan pemeliharaan korektif dan rutin preventif yang dilakukan secara terus menerus. Hal ini dilakukan agar tidak terjadi gangguan yang berkepanjangan sehingga menyebabkan pemadaman secara tibatiba dan akan berpengaruh terhadap tingkat kepuasan pelanggan sebagai pihak penerima pelayanan publik.

Sebagai usaha dalam melaksanakan pelayanan keberlangsungan dengan mutu pendistribusian tenaga listrik yang efisien, maka diimplementasikan sebuah sistem yang dapat memberikan bentuk pelayanan dengan keandalan sistem distribusi yang dapat memberikan sebuah overview persempitan territory akan luas gangguan yang 
sedang terjadi. Fault Detection Insulation And Restoration (FDIR) merupakan otomasi yang berkerja pada sistem jaringan distribusi yang dapat otomatis bekerja melakukan buka tutup CB (Circuit Breaker) serta LBS (Load Break Switch) pada waktu siklus gangguan terdeteksi dan mampu mengisolasi territory gangguan secara cepat yang kemudian dengan waktu yang tergolong cepat melaksanakan proses pemulihan akan gangguan yang terjadi. [1]

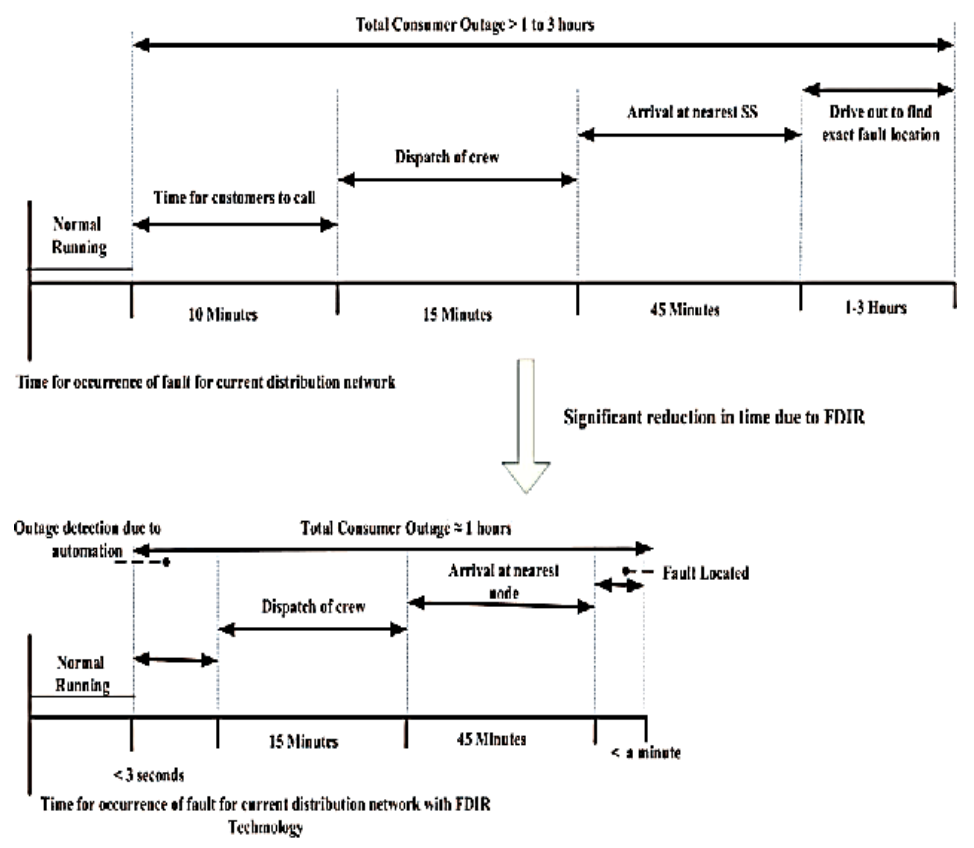

\section{Gambar 1. Sistem Fault Detection Insulation And Restoration untuk Efisiensi Waktu [1].}

Aplikasi ini diharapkan dapat memberikan instruksi panduan kepada operator untuk menangani suatu gangguan yang terjadi, serta mengindikasikan informasi gangguan dengan informasi optimum untuk melaksanakan pengkondisian isolasi area gangguan yang terjadi disertai pelaksanaan re-energize di bagian penyulang yang dilaporkan mendapatkan gangguan. Hal ini akan membantu dalam mengurangi waktu pemadaman yang diakibatkan gangguan yang terjadi.

Dengan penerapan sistem Fault Detection Insulation and Restoration (FDIR) di penyulang ogan yang dimana proses manuvernya sangatlah cepat dan otomatis maka akan terpangkas durasi padam sebelum di pasang sistem Fault Detection Insulation and Restoration (FDIR) ini. Kemudian langsung menentukan titik gangguan di saat terjadi gangguan. 


\section{METODE}

Untuk dapat membuat rancangan alat ini berjalan sesuai dengan perencanaan, maka penulis menggunakan metode Rancang Bangun Alat sebagai acuan.

\subsection{Lokasi Penelitian}

Lokasi penelitian dilakukan di Gardu Induk Sei Juaro pada penyulang Ogan, Gardu Induk Boom Baru pada penyulang Kedondong dan Unit Pelaksana Pengatur Distribusi (UP2D), PT. PLN (Persero) Palembang.

\subsection{Pengumpulan Data}

Pengumpulan data dilakukan sebagai langkah awal dalam sebuah penelitian dan bahan yang mendukung dalam penelitian ini. Data primer, yaitu data yang diambil secara langsung. Data sekunder, yaitu data yang diambil secara tidak langsung melalui studi pustaka dan dokumentasi.

Data primer yang digunakan dalam penelitian ini merupakan data Jaringan Distribusi $20 \mathrm{kV}$ di Penyulang Ogan dan Kedondong, yang diperoleh dari PT. PLN (Persero) WS2JB di UP2D, ULP Rivai, dan UPT Palembang. Pengolahan data menggunakan sistem analisis data yang diperoleh, adapun langkahlangkahnya :

a. Melakukan studi literatur yang berhubungan dengan masalah yang akan dibahas;

b. Mengumpulkan data Single Line Diagram penyulang ogan dan konfigurasi jaringan open loop penyulang ogan dan Kedondong;

c. Mengumpulkan data gangguan dan durasi/lama padam penyulang;

d. Mengumpulkan data beban puncak penyulang;

e. Mengumpulkan data saluran penghantar;

f. Melakukan pengolahan data untuk keandalan jaringan penyulang ogan dan sistem Fault Detection Isolation Restoration;

g. Melakukan analisa terhadap hasil pengolahan data; apakah telah sesuai dengan masalah yang dirumuskan, apabila belum sesuai kembali ke langkah pengolahan data kembali;

h. Menganalisa kesesuaian hasil data terhadap rumusan masalah hingga mendapatkan hasil yang sesuai target output hasil siklus Implementasi FDIR.

\subsection{Kelistrikan Gardu Induk Boom Baru}

Gardu Induk Boom Baru mempunyai dua transformator daya. Tranformator Daya 130 MVA menyuplai 7 penyulang yaitu penyulang Kedondong, Belimbing, Apel, Durian, Chery, Sirsak, dan Blueberry. Sedangkan Tranformator Daya 230 MVA menyuplai 4 penyulang yaitu penyulang Kurma, Anggur, Jeruk dan Kelengkeng. Pada prinsipnya Gardu Induk Boom Baru adalah Gardu Induk penurun tegangan dimana tegangan $70 \mathrm{kV}$ diturunkan mejadi tegangan $20 \mathrm{kV}$. (Sumber : PT. PLN (Persero) WS2JB di UP2D, ULP Rivai, dan UPT Palembang) 


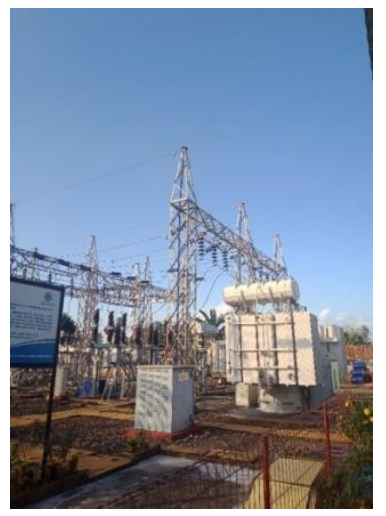

\section{Gambar 2. Gardu Induk Boom Baru}

Penyulang di Gardu Induk Boom Baru terdiri dari 11 penyulang yaitu Tranformator Daya 130 MVA menyuplai 7 penyulang yaitu penyulang Kedondong, Belimbing, Apel, Durian, Chery, Sirsak, dan Blueberry. Sedangkan Tranformator Daya 230 MVA menyuplai 4 penyulang yaitu penyulang Kurma, Anggur, Jeruk dan Kelengkeng. (Sumber : PT. PLN (Persero) WS2JB di UP2D, ULP Rivai, dan UPT Palembang)

\subsection{Skema Kerja Sistem Fault Detection Insulation And Restoration (FDIR) pada Sistem Jaringan Distribusi Loop}

Penyulang yang memiliki pola membentuk ring atau loop, dititik beban memungkinkan untuk dilayani sistemnya di dua arah penyulang, sehingga pelayanan lebih terjamin secara berkelanjutan dengan kemampuan daya yang berkualitas baik dikarenakan rugi tegangan menjadi lebih rendah. [2].

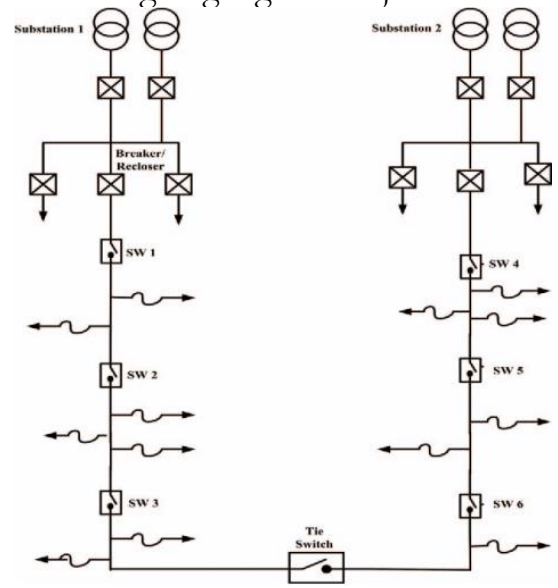

Gambar 3. Sistem Jaringan Distribusi Loop 
Gambar 3. Menunjukan sistem Loop pada konfigurasi jaringan distribusi antara 2 penyulang yang terhubung di tie switch normally open (NO) yang dilengkapi sistem proteksi sebagai pengendali LBS (Load Break Switch) [1]. Pada Tahap isolasi serta proses pemulihan harus mengindikasikan bagian LBS (Load Break Switch) yang dibuka agar dapat mengisolasi territory gangguan serta area LBS (Load Break Switch) yang bisa dimasukan sehingga dapat memasok tegangan untuk territory jaringan yang sudah pada area terbebas dari gangguan yang kemudian mampu menata kembali tipe topologi hubungan kelistrikan di bagian penyulang atau dalam konfigurasi jaringan distribusi spindle. [3]

\subsection{SAIDI (Sistem Average Interuption Duration Index)}

SAIDI atau Sistem Average Interuption Duration Index, adalah indeks rate dari penjumlahan hasil lamanya durasi gangguan yang terjadi di territory pelenggan untuk satu tahun. Penentuan indeks ini didapat dengan cara membagi semua jumlah dari keseluruhan terjadinya gangguan yang terjadi di bagian pelanggan pertahun dengan total keseluruhan jumlah pelanggan dengan total jam/pelanggan [5], dimana perhitungannya menggunakan rumus berikut :

SAIDI $=\frac{\text { jumlah lamanya gangguan di sisi pelanggan }}{\text { jumlah seluruh pelanggan }}$

SAIDI $=\frac{\sum U i \cdot N i}{\sum N i}$ jam pelanggan per tahun

Dengan :

$\mathrm{Ui}=$ lama gangguan rata-rata

$\mathrm{Ni}=$ banyak pelanggan pada suatu titik

\subsection{Energy Not Sold (ENS)}

Energy Not Sold (ENS) adalah suatu perhitungan daya yang tidak terjual ke pelanggan diakibatkan terjadinya pemadaman disisi pelanggan dikarenakan terjadinya gangguan [6], dengan rumus :

$$
\begin{aligned}
& \mathrm{ENS}=\mathrm{I} \cdot \mathrm{V} \cdot \sqrt{3} \cdot \cos \varphi \cdot \text { Lama Padam (hours) (KWh) } \\
& \mathrm{V}=\text { Tegangan Sistem (Volt) } \\
& \mathrm{I}=\text { Arus Beban (Ampere) } \\
& \sqrt{3}=1,732 \\
& \cos \varphi=\text { Faktor Daya sistem. } \\
& \mathrm{t}=\text { Lama Padam (kwh-kilo watt hour) }
\end{aligned}
$$




\section{HASIL DAN PEMBAHASAN}

\subsection{Single Line Diagram Penyulang Ogan GI Sei Juaro.}

Fungsi penentuan lokasi gangguan harus menggunakan data yang berasal dari telemetri dan relay proteksi, dan mempunyai kemampuan menganalisa informasi adanya petunjuk kelompok pelanggan yang padam [3]. Berikut adapun gambar dari Single Line Diagram (SLD) di penyulang Ogan GI Sei Juaro :

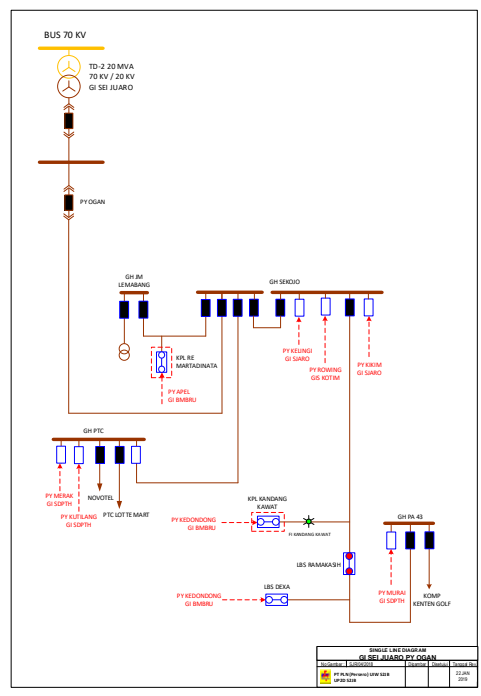

\section{Gambar 4. SLD Penyulang Ogan Sebelum Dilakukan Rekonfigurasi Jaringan \\ (Sumber : PT. PLN (Persero) WS2JB di UP2D, ULP Rivai, dan UPT \\ Palembang)}

\subsection{Single Line Diagram konfigurasi jaringan Penyulang Ogan- Kedondong.}

Dengan pola konfigurasi jaringan open loop, dapat dibuat pemasangan titik remote untuk melakukan pengawasan dan pengumpulan informasi keadaan serta akan dilakukan pegoperasian otomasi dengan sistem Fault Detection Insulation And Restoration (FDIR) yaitu pada masing-masing penyulang dan titik temu kedua penyulang. Berikut gambar setelah direkonfigurasi jaringan di penyulang Ogan GI Sei Juaro dengan penyulang Kedondong GI Boom Baru : 


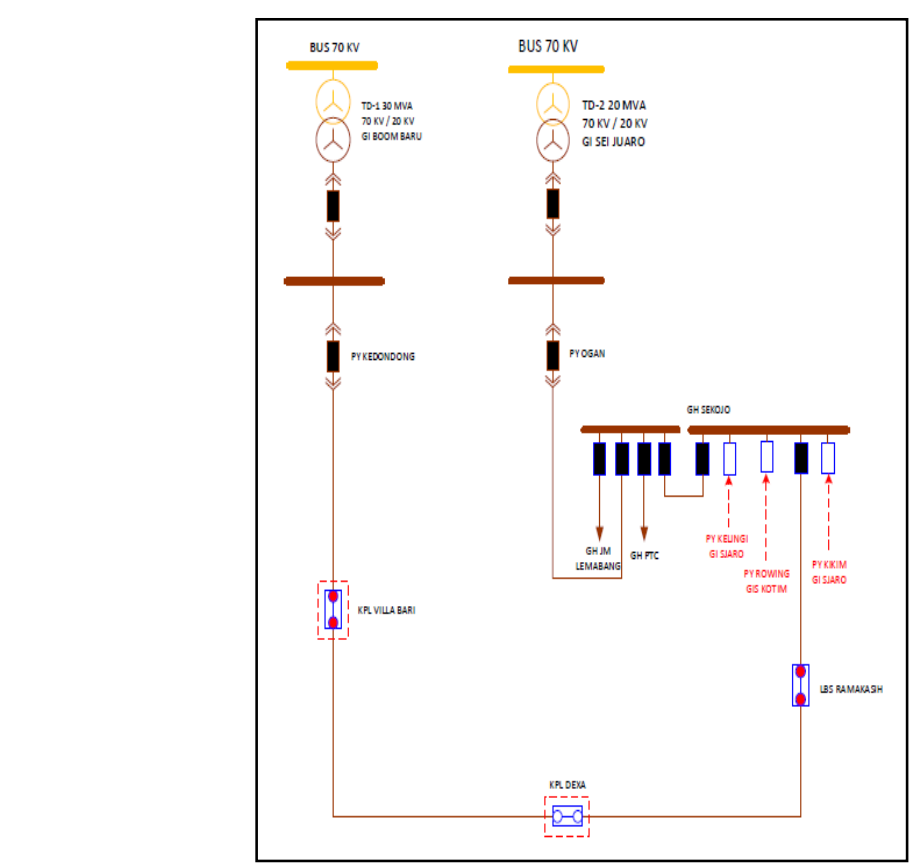

\section{Gambar 5. SLD Penyulang Ogan Setelah Dilakukan Rekonfigurasi Jaringan Dengan Penyulang Kedondong. \\ (Sumber : PT. PLN (Persero) WS2JB di UP2D, ULP Rivai, dan UPT Palembang)}

Melalui remote ini, informasi pengukuran dari titik tersebut diproses secara real time kemudian dinversi dari data analog menjadi data digital untuk dikirim ke master station. Sehingga data tersebut bisa langsung ditampilkan ke layer monitor dan dispatcher dapat mengawasi dan juga melihat alarm untuk mengetahui jika terjadi gangguan di penyulang tersebut.

\subsection{Data Lama Padam Dan Gangguan Penyulang}

Dari data tabel 1. dapat kita lihat bahwa lamanya penormalan penyulang di total per januari-mei 2019 ada 0,5 jam dimana tidak ada daya yang terjual ke pelanggan yang dapat jual, dikarenakan apabila petugas tidak dengan cepat memanuver daya di pernyulang tersebut.

Tabel 1. Data lama padam penyulang Ogan per Januari 2019

\begin{tabular}{lcccc}
\hline \multicolumn{1}{c}{ Jenis } & $\begin{array}{c}\text { Jam } \\
\text { Padam }\end{array}$ & $\begin{array}{c}\text { Jam } \\
\text { Nyala }\end{array}$ & $\begin{array}{c}\text { Lama } \\
\text { Padam }\end{array}$ & $\begin{array}{c}\text { Beban Sebelum } \\
\text { Padam }\end{array}$ \\
\hline $\begin{array}{l}\text { Gardu } \\
\text { Induk }\end{array}$ & $09: 54$ & $09: 58$ & $0: 4$ & 31 \\
\hline $\begin{array}{l}\text { Gardu } \\
\text { Induk }\end{array}$ & $15: 37$ & $15: 42$ & $0: 5$ & 0 \\
\hline
\end{tabular}


(Civil Engineeering, Elektrical Engineeering and Industrial Engineeering)

Vol. 17, No : 2, Oktober 2020 , p-ISSN:1907-5243, e-ISSN: 2655-8416

\begin{tabular}{lcccc}
\hline $\begin{array}{l}\text { Gardu } \\
\text { Induk }\end{array}$ & $08: 27$ & $08: 47$ & $0: 20$ & 62 \\
\hline $\begin{array}{l}\text { Gardu } \\
\text { Induk }\end{array}$ & $03: 22$ & $03: 28$ & $0: 6$ & 57 \\
\hline
\end{tabular}

Total durasi padam 0,5 jam

(Sumber : PT. PLN (Persero) WS2JB di UP2D, ULP Rivai, dan UPT Palembang)

Pertimbangan jarak yang jauh serta informasi posisi territory gangguan menjadi salah satu kendala petugas untuk mengetahui territory di sisi penyulang. Pada situasi ini, petugas dianjurkan untuk menitikberatkan titik padam tidak di sisi penyulang, sehingga para pelanggan di penyulang tersebut tidak kehilangan energi yang berupa daya listrik di sisi user sebaiknya titik padam di fokuskan di sisi Gardu Hubung untuk melakukan manuver dengan penyulang lain.

\subsection{Data Beban Puncak Siang dan Malam}

Untuk menyuplai sebagian beban pada penyulang, kita harus mengetahui besar dari total daya di saat kondisi beban yang memungkinkan untuk dilakukan proses manuver pasokan daya listrik, sehingga data beban puncak dibutuhkan sebagai data pendukung untuk mendapatkan nilai selisih dari beban puncak antar titik remote.

Tabel 2. Pengukuran Arus saat beban puncak untuk 4 titik remote

\begin{tabular}{cccc}
\hline \multirow{2}{*}{ No. } & \multirow{2}{*}{ Penyulang } & \multicolumn{2}{c}{ Beban Puncak (A) } \\
\cline { 3 - 4 } & GH Sekojo & 51 & Malam \\
\hline 1 & KPL Ramakasih & 13,69 & 53,46 \\
\hline 2 & KPL Dexa & 0 & 15,24 \\
\hline 3 & KPL Villa Bari & 50 & 0 \\
\hline 4 & (Sumber : PT. PLN (Persero) WS2JB di UP2D, ULP Rivai, dan UPT Palembang)
\end{tabular}

Data Arus beban puncak sebagai data pendukung untuk mendapatkan nilai posisi skenario kondisi gangguan, terlihat nilai arus beban puncak per Mei 2019 :

Tabel 3. Pengukuran Arus saat beban puncak per Mei 2019

\begin{tabular}{llll}
\hline \multirow{2}{*}{ No. } & \multirow{2}{*}{ Penyulang } & \multicolumn{2}{l}{ Beban Puncak (A) } \\
\cline { 3 - 4 } & & Siang & Malam \\
\hline 1 & Ogan & 97 & 111 \\
\hline 2 & Kedondong & 167 & 91 \\
\hline & (Sumber : PT. PLN (Persero) & WS2JB di UP2D, ULP Rivai, dan UPT Palembang)
\end{tabular}

\subsection{Data Saluran Penghantar}

User menerima energi dari tiang TR (Tegangan Rendah) yang merambat melalui konduktor kawat SR (Sambungan Rumah) yang kemudian berakhir di 


\section{Jurnal TEKNO}

(Civil Engineeering, Elektrical Engineeering and Industrial Engineeering)

Vol. 17, No : 2, Oktober 2020 , p-ISSN:1907-5243, e-ISSN: 2655-8416

pengukur listrik sebagai indikator kehadiran listrik di area user/pengguna energi. [4]

Tabel 4. Panjang SUTM dan SKTM penyulang Ogan-Kedondong

\begin{tabular}{|c|c|c|c|c|c|}
\hline No & Penyulang & Arah & $\begin{array}{l}\text { Tegangan } \\
(\mathrm{kV})\end{array}$ & $\begin{array}{c}\text { Panjang } \\
\text { SUTM (m) }\end{array}$ & $\begin{array}{c}\text { Panjang } \\
\text { SKTM (m) }\end{array}$ \\
\hline 1 & Ogan & GH Sekojo & 20 & - & 4300 \\
\hline 2 & Ogan & LBS Ramakasih & 20 & 1705 & - \\
\hline 3 & Kedondong & KPL Villa Bari & 20 & 640 & 719 \\
\hline 4 & Kedondong & KPL Dexa & 20 & 833 & - \\
\hline
\end{tabular}

\section{Gambar 6. KPL Villa Bari (a) \& KPL Dexa (b)}

\subsection{Simulasi Pengoperasian Fault Detection Insulation and Restoration (FDIR)}

Sebelum melakukan analisa simulasi pengoptimalan peningkatan kehandalan dengan menggunakan sistem Fault Detection Insulation and Restoration (FDIR) di penyulang Ogan Gardu Induk Sei Juaro dengan titik manuver di KPL (Key Point Line) di penyulang Kedondong Gardu Induk Boom, kita harus mengetahui titik permasalahan apa yang terjadi sehingga dilakukan nya proses manuver di penyulang kedondong.

Simulasi diawali dengan membuat simulasi yang dapat mendeteksi territory gangguan disertai penormalan penyulang yang dapat dilakukan dalam waktu tidak lebih dari 1 menit. Hal itu akan mengurangi ENS di penyulang Ogan. [3] Sebelum melakukan mekanisme pengoperasian Fault Detection Insulation and Restoration (FDIR) kita harus mengetahui berapa manuver beban. Untuk menyuplai sebagian beban pada penyulang Kurma, kita harus mengtahui total daya dan kondisi beban yang memungkinkan untuk dilakukan manuver pasokan daya listrik. Dari gambar konfigurasi jaringan open loop Penyulang Ogan-Kedondong, Data lama padam 
(Civil Engineeering, Elektrical Engineeering and Industrial Engineeering)

Vol. 17, No : 2, Oktober 2020 , p-ISSN:1907-5243, e-ISSN: 2655-8416

penyulang Ogan per Januari 2019 dan Data Pengukuran Arus saat beban puncak per Mei 2019, maka dapat dihitung selisih beban puncak antar titik remote yaitu :

a. Selisih antar penyulang Kedondong dan KPL Villa Bari :
Beban puncak siang
$=167 \mathrm{~A}-50 \mathrm{~A}$
$=117 \mathrm{~A}$
Beban puncak malam
$=91 \mathrm{~A}-54 \mathrm{~A}$
$=38 \mathrm{~A}$

b. Selisih antar penyulang KPL Villa Bari dan KPL Dexa :
Beban puncak siang
$=50 \mathrm{~A}-0 \mathrm{~A}$
$=50 \mathrm{~A}$
Beban puncak malam
$=54 \mathrm{~A}-0 \mathrm{~A}$
$=54 \mathrm{~A}$

c. Selisih antar penyulang Ogan dan GH Sekojo :
Beban puncak siang
$=97 \mathrm{~A}-51 \mathrm{~A}$
$=46 \mathrm{~A}$
Beban puncak malam
$=111 \mathrm{~A}-53,46 \mathrm{~A}$
$=57,54 \mathrm{~A}$

d. Selisih antar GH Sekojo dan KPL Ramakasih :
Beban puncak siang
$=51 \mathrm{~A}-13,69 \mathrm{~A}$
$=37,31 \mathrm{~A}$
Beban puncak malam
$=53,46 \mathrm{~A}-15,24 \mathrm{~A}$
$=38,22 \mathrm{~A}$

e. Selisih antar KPL Ramakasih dan KPL Dexa :
Beban puncak siang
$=51 \mathrm{~A}-0 \mathrm{~A}$
Beban puncak malam
$=53,46 \mathrm{~A}-0 \mathrm{~A}$
$=51 \mathrm{~A}$
$=53,46 \mathrm{~A}$

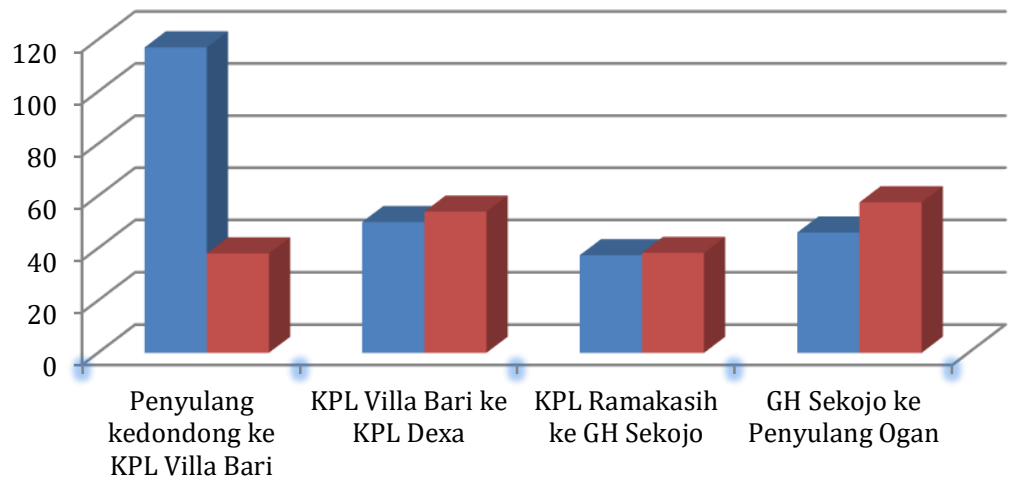

Gambar 7. Grafik Beban puncak untuk konfigurasi jaringan open loop Penyulang Ogan-Kedondong

Setelah dilakukan rekonfigurasi jaringan dikondisi normal, penyulang Kedondong dan penyulang Ogan bertemu pada KPL Dexa yang dalam keadaan open atau terbuka. Berikut ini tampilan konfigurasi jaringan di Human Machine Interface (HMI) SCADA : 


\section{Jurnal TEKNO}

(Civil Engineeering, Elektrical Engineeering and Industrial Engineeering)

Vol. 17, No : 2, Oktober 2020 , p-ISSN:1907-5243, e-ISSN: 2655-8416

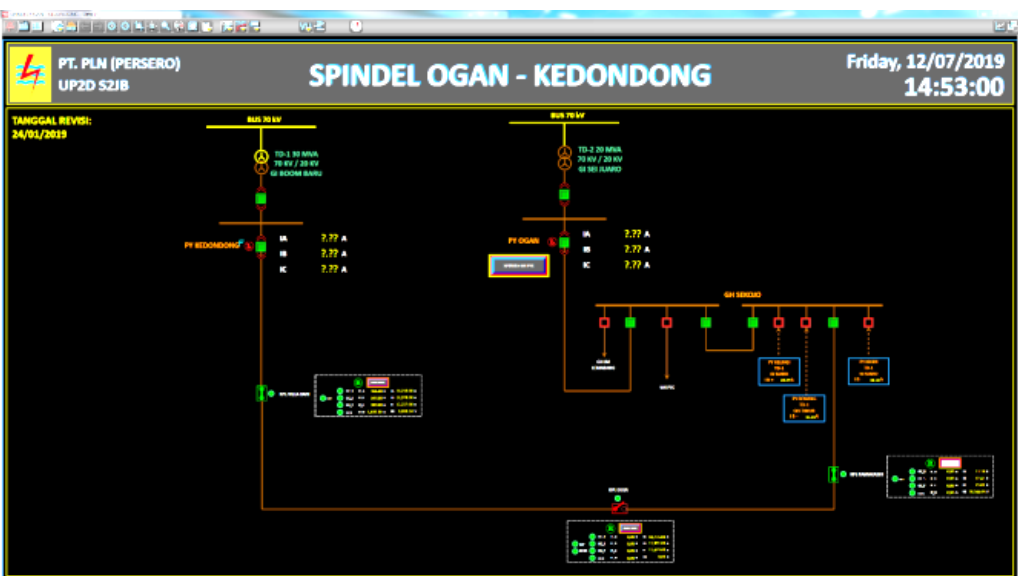

Gambar 8. Konfigurasi Jaringan open loop pada tampilan HMI SCADA

(Sumber : PT. PLN (Persero) WS2JB di UP2D, ULP Rivai, dan UPT

Palembang)

Untuk data penunjang sistem Fault Detection Insulation and Restoration (FDIR) juga harus terinput dengan benar untuk menghindari ketidaksesuaian pada proses penginputan yang membuat sistem tidak beroperasi. [3]

Adapun hal-hal yang harus terinput dalam sistem FDIR antara lain :

1. Line Section di setiap point gambar;

2. Indikasi gangguan yang ada di dalam keypoint,

3. Nilai beban maksimal trafo di dalam satu section jaringan.

Apabila terjadi gangguan pada penyulang Ogan, sistem otomasi Fault Detection Insulation and Restoration (FDIR) akan langsung mengisolasi jaringan dengan memanuver ke penyulang Kedondong. Dalam kurun waktu kurang dari satu menit.

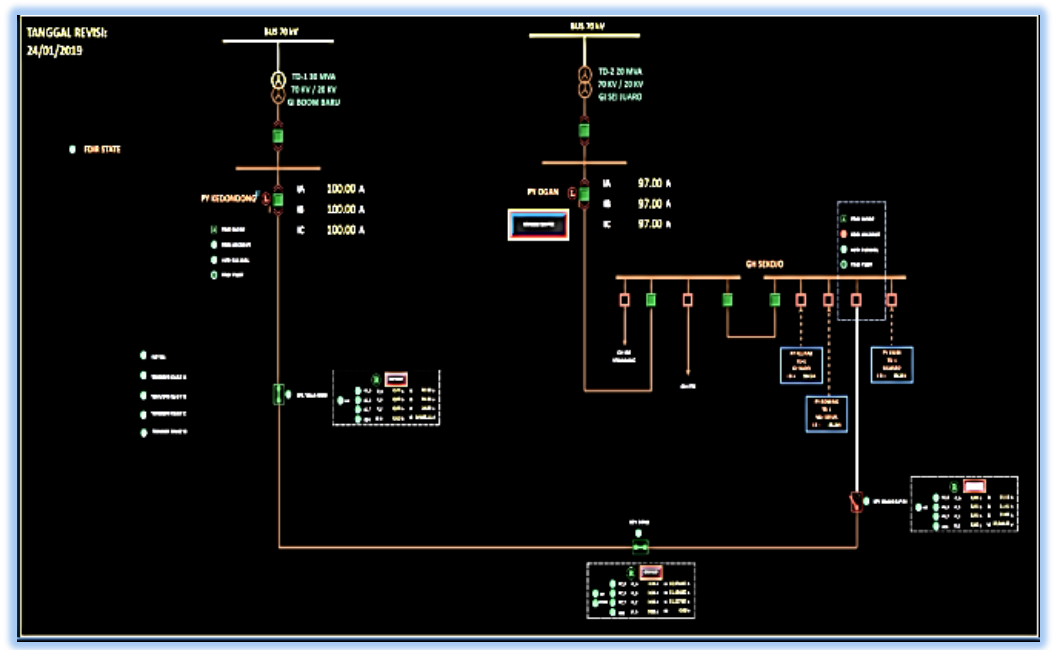




\section{Gambar 9. Skenario Penyulang Ogan-Kedondong setelah kondisi gangguan}

(Sumber : PT. PLN (Persero) WS2JB di UP2D, ULP Rivai, dan UPT Palembang)

Dari posisi skenario kondisi gangguan terlihat posisi open yang terjadi adalah di posisi GH Sekojo terlebih dahulu kemudian LBS Ramakasih terbuka dan langsung memanuver di titik KPL Dexa dari penyulang Kedondong. Dengan kurun waktu 25 detik dengan menggunakan sistem Fault Detection Insulation and Restoration (FDIR). Agar tetap terselamatkan daya yang tersalurkan ke pelanggan meski ada gangguan di antara GH Sekojo dan KPL Ramakasih.

\subsection{Perhitungan Indeks Kehandalan SAIDI (System Average Interruption Duration Index)}

Dari Tabel 1. terjadi gangguan sebanyak 4 kali dengan durasi padam total 0,5 jam selama 1 bulan. Dimana didapatkan perhitungan SAIDI sebagai berikut

$$
\text { SAIDI }=\frac{0,5 \mathrm{jam} \times 788 \text { pelanggan }}{788 \text { pelangan }} \quad=0,5 \mathrm{jam} / \mathrm{bln}
$$

apabila jika kita masukaan sistem Fault Detection Insulation and Restoration (FDIR) disaat terjadi gangguan tersebut dengan kurun waktu 25 detik dalam satu gangguan. Maka didapatkan total durasi padam adalah :

SAIDI $=\frac{0,027 \mathrm{jam} \times 609 \text { pelanggan }}{788 \text { pelangan }}=0,021 \mathrm{jam} / \mathrm{bln}$

\subsection{Perhitungan Nilai ENS (Energy Not Sold)}

Sebagai contoh terjadi gangguan yang mengakibatkan penyulang Ogan mati selama 0,5 jam akibat gangguan pohon dioperasikan melalui Telecontrol SCADA dari dispatcher, dapat dihitung daya yang tidak terjual ke pelanggan yaitu: ENS $=\mathrm{I} \cdot \mathrm{V} \cdot \sqrt{3} \cdot \cos \varphi$. Lama Padam (hours) $=97 \times 20 \mathrm{kV} \times 1,73 \times 0,85 \times 0,5 \mathrm{jam}$ $=1426,38 \mathrm{kWh}$.

Maka jika diubah menjadi rupiah, maka PT.PLN meng alami kerugian sebesar :

$=1426,38 \mathrm{kWh} \times$ Rp. $1.467,28$

$$
=\text { Rp. } 2.092 .906,18 / \mathrm{plg}
$$

Jadi kerugian yang dialami saat perbandingan antara Telecontrol SCADA dan sistem Fault Detection Insulation and Restoration (FDIR) sebesar Rp. 2.092.906,18/plg Adapun untuk menurunkan angka Energy Not Sold (ENS) atau energi yang tidak terjual, maka perlu kita menambahkan sistem Fault Detection 
Insulation and Restoration (FDIR) ini untuk pengoperasiaanya. Untuk melakukan proses manuver jaringan dan meminimalisir territory gangguan dengan kurun waktu kurang dari 1 menit.

\section{SIMPULAN}

Dari penelitian ini dapat disimpulkan oleh peneliti yaitu:

1. Penggunaan sistem Fault Detection Insulation and Restoration (FDIR) dapat meningkatkan keandalan jaringan distribusi dikarenakan proses pengoperasian manuvernya hanya berdurasi 25 detik disertai maneuver sistem Fault Detection Insulation and Restoration (FDIR) pada sisi gangguan GH dapat langsung memanuver jaringan ke penyulang Kedondong. Sedangkan dengan menggunakan Telecontrol SCADA membutuhkan waktu \pm 6 menit jika terjadi satu gangguan dan juga langsung mengakibatkan penyulang Ogan padam total.

2. Menjadikan nilai ENS (Energy not sold) atau nilai daya yang terjual ke pelanggan dapat terus berjalan karena perbandingan pengoperasiannya sangat signifikan. Dimana kerugian yang dialami perusahaan sebesar Rp. 2.092.906,18/plg dari perbandingan pengoperasian Telecontrol SCADA dan sistem Fault Detection Insulation and Restoration (FDIR) selama 1 bulan.

\section{DAFTAR RUJUKAN}

[1]. Palak P. Parikh. Voloh. Mahony, 2013, Distributed Fault Detection, Isolation and Restoration (FDIR) technique for smart distribution system, 66 ${ }^{\text {th }}$ Annual Conference for Protective Relay Engineers.
Date
Added
to
IEEE Xplore: 29
May
2014 ,

DOI: $10.1109 /$ CPRE.2013.6822035.

[2]. Suhandi. Wahatnolo. Tri, 2008, Teknik Distribusi Tenaga Listrik, Jakarta, Departemen Pendidikan Nasional.

[3]. Team PLN Sektor PT. PLN Di Penyulang Ogan Gardu Induk Sei Juaro, 2019.

[4]. Kadir, A, 2006, Distribusi dan Utilisasi Tenaga Listrik, Universitas Indonesia Press, Jakarta.

[5]. Willis, H. Lee. 2004. Power Distribution Planning Reference Book Second Edition, Revised and Expanded, Raleigh, Nort Carolina, U.S.A. New York-Basel, Marcel Dekker, Inc.

[6]. I.W.Sukadana, I.N.Suartika, 2019, Optimalisasi LBS Motorized Key Point Pada Jaringan Distribusi 20kV Untuk. Meningkatkan Keandalan Sistem, Jurnal Teknik Elektro dan Vokasional (JTEV), Universitas Negeri Padang, Vol.5, No.1.1 (2019). 